\title{
Autoría, mutaciones y migraciones. Presencias de cineas- tAS ESPAÑoles EN El MUSEO: AlBert SERRA
}

\section{Authorism, Mutations, and Migrations. Presence of Spanish Filmmakers in the Museum: Albert Serra}

\author{
Dra. Laura GÓMEZ VAQUERO \\ Profesora asociada de la Universidad de Salamanca, España \\ E-mail: laura.g.vaquero@usal.es \\ (iD) https://orcid.org/0000-0001-6532-248X
}

Fecha de recepción del artículo: 15/09/2019

Fecha de aceptación definitiva: 23/10/2019

\begin{abstract}
RESUMEN
Uno de los espacios que, desde más de una década, resulta una vía no solo de exhibición sino también de financiación de proyectos surgidos de cineastas españoles cuya obra encuentra difícil acomodo en salas de cine convencionales es el museo y las salas de exposiciones. Esta migración de los cineastas a la institución museística se debe a la crisis que aqueja a la industria del cine, de manera especial en España. Nuestro propósito en este texto es ir más allá del análisis de los productos resultado de dichas migraciones para encontrar las circunstancias y condiciones discursivas en que dichas migraciones se producen. El cineasta catalán Albert Serra, cuyos trabajos han estado presentes en festivales, salas de cine, museos y galerías, y cuya trayectoria se caracteriza por las continuas reescrituras y reelaboraciones, resulta una figura idónea para analizar de qué manera se inserta éste en espacios de exhibición. Tal y como argumentaremos, en su caso, la categoría de «autor» resulta útil para explicar y promocionar su obra.
\end{abstract}

Palabras clave: Cine y museo; cine español; autor; director mediático; Albert Serra.

\begin{abstract}
One of the places that, for more than a decade, has been a means not only of exhibition but also of financing projects arising from Spanish filmmakers whose work finds it difficult to fit into conventional cinemas is the museum and the exhibition halls. This migration of filmmakers to the museum is due to the crisis afflicting the film industry, especially in Spain. Our purpose in this text is to go beyond the analysis of the products resulting from these migrations to find the circumstances and discursive conditions in which these migrations take place. The Catalan filmmaker Albert Serra, whose work is characterised by rewriting and reworking and has been present at festivals, cinemas, museums and galleries, is an ideal figure to analyse how this is inserted in exhibition spaces. As we will argue, in his case, the category of "author» is useful to explain and promote his work.
\end{abstract}

Key words: cinema and the museum; Spanish Cinema; author; media filmmaker; Albert Serra. 


\section{Introducción. La migración de cineastas españoles al museo}

En el número inaugural de la revista Cahiers du cinema España (Caimán. Cuadernos de cine desde enero de 2012), publicado en mayo de 2007 y titulado "Tiempos de futuro. 29 miradas al cine que viene», se incluía una sección, "Miradas hacia el futuro", en la que se interrogaba a determinados cineastas españoles y latinoamericanos sobre su posición dentro de un escenario marcado por «la naturaleza cambiante de las imágenes» (Heredero, mayo de 2007, p. 10). De entre los diversos cineastas convocados (Isabel Coixet, Paz Encina, Manuel Gutiérrez Aragón, Julio Bressane, Enrique Urbizu, Pablo Trapero y Pedro Almodóvar, entre otros), el encargado de abrir el turno de respuestas es Víctor Erice, cineasta que los críticos y estudiosos llevaban considerando como un director con una mirada propia (Benet, 2005). A la pregunta de «Cómo afronta usted, como creador, la práctica del cine frente a un futuro ya inmediato de cambios y transformaciones en la naturaleza de las imágenes?», Erice respondía de la siguiente manera:

"Habría que precisar... Preguntarnos también de qué hablamos o queremos hablar cuando, quizás por inercia, hoy decimos la palabra cine. Aunque se puedan ver, de cuando en cuando, buenas películas, la sensación -algo más que la sensación- que uno tiene, cuando echa una ojeada a su alrededor, es que el cine es cosa del pasado. Y que el Audiovisual, con todo lo que eso supone, constituye nuestro presente, lo establecido» (Heredero, mayo de 2007, p. 11).

Tal y como explicaría años después Ángel Quintana en su texto Después del cine. Imagen y realidad en la era digital (2012), el cine había vivido una transformación sustancial desde la fecha simbólica de 1995 (cuando cumplía 100 años de existencia como medio) hasta entonces. Atravesado por el intenso cambio tecnológico que tuvo lugar desde esa década, el cine había dejado de ser aquello que era para transformarse en otra cosa: ya no era una expresión cultural que se consume de manera colectiva, ni un medio que contempla una distancia cercana respecto a su objeto (frente a la imagen analógica, la imagen de síntesis); sus procesos de trabajo son distintos y su indistinción respecto a otras expresiones audiovisuales resulta cada vez más difícil. El futuro del cine, afirmaba el investigador catalán, se encontraba determinado por la conversión de todo en imagen, así como por la multiplicación de pantallas.

Es precisamente este último fenómeno el que José Luis Guerín, el segundo de los cineastas interrogados por la revista Cahiers España, destacaba como principal novedad en lo que a consumo del cine se refiere. A la pregunta de "¿Cómo piensa usted que esas transformaciones van a condicionar las nuevas formas de consumir imágenes y de relacionarnos con ellas?», el cineasta respondía: «Tienen la forma de una desacralización: el tiempo sagrado de la pantalla frente al tiempo doméstico del portátil o del móvil» (Heredero, mayo de 2007, p.11). Esta respuesta, con ecos en la "Omnipantalla» de Lipovetsky y Serroy (2007), anuncia también que -más allá de si es positivo o negativo-, este cambio de formato no solo implica un consumo individual y potencialmente múltiple (frente al colectivo y único de la sala), sino también un cambio en el tipo de posición condicionada que adquiriría el espectador actual: en un escenario en el que "lo cinematográfico» se diluye entre el magma de "lo audiovisual», lo que implicaría la "muerte del cine» y el surgimiento del llamado "post-cine» (Serge Daney, 1991), acaece también la muerte de la cinefilia, anunciada ya por Susan Sontag en 1996 en el seno de la celebración del centenario del cine. Más allá de los posicionamientos 
radicales al respecto, ambas implicarían, más bien, como indicarían Jonathan Rosenbaum y Adrian Martin años después en Movie Mutations: The Changing Face of World Cinephilia (2003), la desaparición de una determinada cultura cinematográfica para dar lugar a otra en la que la cinefilia adopta nuevas formas, todo ello producto de un cambio de paradigma en el terreno de lo cultural.

El descenso progresivo de salas de cine, que por cierto resulta más acusado en España que en otros países europeos (Deltell y García, noviembre de 2013), resulta ser el síntoma más evidente de una crisis en la industria que parecía más profunda de las que han asolado al cine español a lo largo de la historia ${ }^{1}$. La invalidez de ciertas estrategias de comercialización ha llevado a algunos cineastas a migrar a otros «lugares»; por ejemplo, a las empresas de exhibición de contenido audiovisual mediante plataforma en línea, como Netflix. Tal es el caso de Elías León Siminiani, un cineasta de formación que, desde sus comienzos, alternó su trabajo en la televisión (en las series El sindrome de Ulises [Antena 3, 2007-2008], Cambio de clase [Disney Channel, 20062009] y Córtate [Cuatro, 2005]) con la realización de proyectos independientes que han circulado por festivales de cine nacionales e internacionales (la serie Conceptos clave del mundo moderno [1998-2009], Limites $1^{a}$ persona [2009], Mapa [2012] y Apuntes para una pelicula de atracos [2018]), y que recientemente ha realizado las series documentales con altos índices de audiencia El caso Asunta (Operación Nenúfar) (2017) y El caso Alcàsser (2019) para Antena 3 y la plataforma Netflix, respectivamente.

Otro de los lugares que, ya desde poco más de una década, resulta una vía no solo de exhibición sino también de producción de proyectos que encuentran difícil acomodo en salas de cine convencionales y plataformas de VOD es el museo y las salas de exposiciones. Así lo apuntaba otro de los cineastas interrogados en la revista, Basilio Martín Patino, quien, tras ensalzar el carácter democratizador de las nuevas tecnologías de la era digital, indicaba:

"Otra vertiente más lúdica, en las nuevas formas de consumo y relación con las imágenes, es extraerlas del engranaje de las antiguas salas de butacas del teatro a la italiana [...], en competencia cada vez más dura de la televisión ly de otros formatos audiovisuales como, por ejemplo, los videojuegos y las variantes diversas del audiovisual presentes en La Web, habría que añadir]. Las salas de exposición se prestan a otra dimensión, otras perspectivas, otro sentido de la fiesta, con muchas oportunidades de crecer placenteramente, vitalmente ${ }^{2}$ (Heredero, mayo de 2007, p. 32).

1. La crisis ha acompañado al cine español a lo largo de su historia, tal y como certifica el volumen Once miradas sobre la crisis y el cine español, coordinado por Luis Alonso y publicado en 2003 por Ocho y Medio, donde se encuentran capítulos con títulos tan reveladores como «Una crisis tan interminable como enmascarada» (Txomin Ansola González), «¿Dónde está el cine español?» (Emilio Carlos García Fernández) y «iNo encuentro el punto de giro!» (Carmen Arocena Badillos). De entre los textos pertenecientes a diversos miembros de la histórica A.E.H.C. (Asociación Española de Historiadores del Cine), queremos destacar especialmente: «La crisis como flujo», escrito por Josetxo Cerdán y José Luis Castro de Paz y "La crisis imaginada de un cine sin público», de Cristina Puyol y José Luis Fecé.

2. Respecto a la función del museo, Patino explicaba en otra entrevista: «Sacar el concepto de museo de su urna aristocrática para ampliarlo a un ambiente más urbano, más crítico, darle más vuelo, que es lo que hacen los grandes museos. La Tate acaba de meter un tobogán y aquí parece un sacrilegio. Supongo que eso es la posmodernidad, discutir la autoridad suprema del artista y situarle a la altura de la gente, que es lo que a mí me ha interesado siempre» (De Tuesta, 3 de noviembre de 2006). 
La migración del cine de la black box al white cube, de un espacio caracterizado por la inmersión colectiva con un tiempo cerrado a otro que contempla la posición situada y una temporalidad abierta, implica una transformación de las formas cinematográficas y de las experiencias espectatoriales que, para cineastas como Patino, resulta una vía creativa potencialmente fructífera y sugerente a explorar, si bien, no exenta de problemas, como han insistido en señalar los estudiosos que se han acercado a complejo asunto (Catalá, 2012; Jarque, 2012; Zunzunegui, 2010). La ubicación y traslación del cine a la sala del museo conlleva, en la mejor expresión de su forma, una conciencia de los elementos involucrados en esa puesta en relación entre medios; tal y como afirma Zunzunegui, el movimiento bidireccional del museo al cine y del cine al museo «sólo puede hacerse al precio de tener en cuenta que la alianza sólo puede fundarse sobre el reconocimiento de las diferencias, de las distancias que existen tanto entre la dimensión institucional como estética de ambos territorios» (2010, p. 83).

El interés de la «institución-arte» hacia el «medio-cine» tiene una serie de antecedentes que, precisamente, han sido puestos de manifiesto por diversos investigadores durante las dos últimas décadas; una tarea ésta que se plantea ante el riesgo de que se pierda la conciencia de la extrañeza implícita en la migración de un medio (imagen en movimiento) a un espacio no natural (museo) y las implicaciones físicas y psicológicas que esta dislocación espectatorial conlleva (Uroski, 2010 y 2014). Sin embargo, la presencia del cine en las diversas instituciones artísticas españolas resulta, desde hace un par décadas, más frecuentes y heterogéneas.

Un aspecto clave, no demasiado reseñado en los textos que abordan la cuestión (a señalar como excepción: Zunzunegui, 2010), es la transformación de las instituciones artísticas, que han implicado una redefinición del papel social del museo contemporáneo (amenazado, por otra parte, por la existencia, desde los años 60, de las experiencias estéticas y artísticas más allá de sus muros). Durante las últimas décadas y de manera progresiva, los centros de arte ya no se conciben únicamente como espacios expositivos concebidos como una suerte de recorrido por la historia del arte, sino como promotores de proyectos artísticos y divulgadores e impulsores de la creación artística, entre otras cualidades ${ }^{3}$. La imagen en movimiento se encuentra presente en sus diversos formatos y funciones en los centros artísticos: ya sea como complemento explicativo y didáctico a las verdaderas «estrellas» de la exposición (y aquí se estaría empleando el audiovisual como fuente histórica o complemento visual); ya como hecho cultural o artístico concreto, cuya distancia temporal con el presente lo torna en artefacto histórico (y su presencia en el museo implica su inclusión en un cierto relato de "la historia del arte», así como una museificación del cine); o como artefacto artístico, producto directo de un artista -o cineasta--, en lo que se ha llamado cinéma d'exposition o screen art (Weinrichter, 2006).

La presencia de cineastas españoles en centros de arte contempla todos los casos. En cuanto al primero de ellos, los recorridos temáticos de su colección que el MNCARS propone (frente a los criterios cronológicos, de tipo geográfico y de autoría [Ávila, 2010]) suelen incluir material audiovisual que funciona, en su mayor

3. Una de las más importantes, el impulso del turismo y la vitalización (sobre todo, económica) del territorio. Ana Ávila estudia en especial el papel principal de los museos de arte contemporáneo en las cuatro últimas décadas: "proyectar una nueva imagen sobre la zona e incidir en diversas facetas de la realidad urbana». (Ávila, 2010: 199). 
parte, como elemento contextual. Del segundo, podemos señalar la inserción de la figura de Val del Omar en el terreno artístico hasta el punto de, como ya señalaba Rafael R. Tranche, haberse efectuado una "entronización institucional del personaje» (2012, p. 121), consistente en parte en «su (re)conversión artística, por más que él se moviera siempre en el territorio del cine y de la industria audiovisual» (p. 122). Por último, el tercero de los casos se da precisamente en los tres cineastas que he venido nombrando hasta ahora.

Erice, Guerín y Patino son representantes de una generación en la que el cine era una expresión cultural localizada y específica pero que, sin embargo, comenzaban ya a comprobar aquello que, de manera diferente, expresaban en la entrevista de Cabiers. Víctor Erice, cuyas dificultades para sacar adelante proyectos le habían convertido en una figura maldita dentro del cine español, acababa de participar en la iniciativa que abriría el camino hacia la inmersión del cine en el centro de arte (de la que nos ocuparemos más adelante): la exposición comisariada para el CCCB/Centro Pompidou por el crítico Alain Bergala y el que fuera director de exposiciones del centro catalán Jordi Balló, titulada "Erice-Kiarostami. Correspondencias» (2006). En lo que respecta a José Luis Guerín, al poco de publicarse la entrevista, el 10 de junio de 2007, el cineasta estrena en el Pabellón de España de la 52 $2^{\mathrm{a}}$ Bienal de Venecia una instalación surgida de sus inmediatos trabajos previos, En la ciudad de Sylvia (2007) y Unas fotos en la ciudad de Sylvia (2007), que se expondrá al año siguiente en el CCCB. Por último, para cuando se publica la revista, Patino ya había dado muestras de su capacidad para traspasar los límites del medio en que se había formado, el cine; en concreto, tanto con trabajos para televisión (La seducción del caos [1991] y la serie para Canal Sur Andalucía, un siglo de fascinación [1994-1996]) como con proyectos culturales con financiación pública como, por ejemplo, la videoinstalación creada, junto al diseñador de hologramas Pablo Martín Pascual, para Las Edades del Hombre en la catedral vieja de Salamanca (1993).

Pero también hay una nueva generación de jóvenes cineastas que se muestran sensibles respecto a esta nueva vía. Si retornamos al clarividente "Miradas sobre el futuro", encontramos a Albert Serra, quien se muestra terminante respecto al futuro del cine español:

"Los verdaderos cineastas, los que no querrán acogerse al subsidio elitista y kitsch que les ofrecerán los museos, no podrán sobrevivir, al menos dentro de la tradición industrial que estaba implícita en la definición del cine desde su nacimiento» (Heredero, mayo de 2007, p. 30).

Por su parte, Isaki Lacuesta se describía como «dispuesto a todo tipo de experiencias», puesto que "lo inesperado nos aguarda" (Heredero, mayo de 2007, p. 17).

Para 2010, la migración de determinados cineastas españoles hacia los centros de arte y museos resulta ya un hecho. Es en torno a ese año cuando aparecen, en publicaciones académicas y divulgativas españolas, diversos textos que exploran la integración del «medio-cine» en el «espacio-museo» (Weinrichter, 2010 y Tranche, 2012) ${ }^{4}$. Estos

4. Algunos de estos textos resultan determinantes en cuanto a la situación de crisis que aqueja al cine; así, Rafael R. Tranche afirma: «el cine se encuentra ante una de sus más agudas y profundas crisis, que probablemente desemboque en su muerte, al menos como manifestación cultural", lo que deriva en un escenario en el que se encuentran "los centros de arte reclamando su cadáver y un 
textos dan fe de una tendencia que encuentra su principal razón de ser en la crisis que aqueja al cine español, así como a la predisposición de la institución museística a incorporar un medio que, hasta entonces, había estado presente en el "cubo blanco» de manera limitada y bajo unas determinadas condiciones.

Esta tendencia ha ido en aumento durante los últimos años. Si nos centramos en los cineastas que ya han aparecido en este texto, todos ellos han desarrollado proyectos en el seno de la institución artística desde 2010. Guerín, Serra y Lacuesta colaborarían en el proyecto continuación de esas correspondencias desarrolladas entre Erice y Kiarostami que adoptó el nombre de «Todas las cartas. Correspondencias fílmicas» (2011-2012), la exposición comisariada por Jordi Balló para el CCCB. Víctor Erice prepara una videoinstalación para el Museo de Bellas Artes de Bilbao en octubre de 2019 que, según declaraciones a diario local, "no tendrá que ver con el cine a nivel argumental, aunque sí lógicamente con la imagen al tratarse de una videoinstalación" (Belategui, 30 de abril de 2019). José Luis Guerín realizó una instalación para el Museo de Arte Contemporáneo Esteban Vicente titulada La Dama de Corinto. Un esbozo cinematográfico, expuesta entre diciembre de 2010 y agosto de 2011, para pasar, en una versión reducida, al Centro Pompidou (7 de diciembre de 2012 - 7 de enero de 2013). Por su parte, el Centro José Guerrero (Diputación de Granada) propuso, entre octubre de 2006 y enero de 2007, una mirada particular a la obra de Basilio Martín Patino, comisariada por Carlos Martín, en forma de exposición, ciclo de cine, ciclo de conferencias y edición de un libro-catálogo, que pasó al Círculo de Bellas Artes de Madrid en julio de 2007; titulada Espejos en la niebla (18 de abril de 2008 - 8 de junio de 2008), en ella, el cineasta salmantino tuvo ocasión, en sus propias palabras, de «experimentar en el campo audiovisual ampliando sus límites más allá del constreñido espectáculo a la italiana, una sala oscura con butacas", gracias a "las espectaculares posibilidades expresivas que aporta la nueva era digital» (Martín Patino, 2008, p. 15). Por último, tanto Isaki Lacuesta como Albert Serra, nacidos ambos el año 1975, llevan varios años revelando su sintonía con los centros de arte (y al revés) y han conseguido formalizar su relación hace apenas un año: el Centro Nacional de Arte y Cultura Georges Pompidou dedica al primero una retrospectiva que estuvo visible entre el 26 de noviembre de 2018 hasta el 6 de enero de 2019; el segundo acaba de presentar su último trabajo audiovisual, Personalien (2019), en el MNCARS.

Junto a estos casos, hay otros nombres propios que han hecho su aparición en museos y espacios exhibitivos durante los últimos años como, por ejemplo, Pere Portabella, Andrés Duque y Pilar Monsell. Los modos en que estos cineastas han sido integrados en la institución museística han sido diversos, como también lo son los propios creadores y espacios involucrados. Tal y como indicaba ya Rafael R. Tranche, "el ensanchamiento o la pérdida de fronteras del arte contemporáneo (donde todo es posible, hasta el cine) [...] permite asimilar como «artística» la obra de (solo) determinados cineastas e incluso promoverla y financiarla» (Tranche, abril de 2012, p. 76). Un proceso de migración que, en muchas ocasiones, implica la conversión del original en un artefacto que difícilmente podría ya denominarse "cine»; pero, que en otras, supone única y exclusivamente la traslación, sin modificaciones, de la película original a un habitáculo artístico.

nutrido grupo de cineastas refugiados en su interior buscando el modo de seguir "vivos" (Tranche, 2012, p. 75). Debemos señalar, también, la publicación del texto de Antonio Weinrichter, "De película. El cine se instala en el museo» en la revista de arte Exit Express en mayo de 2006. 
Las condiciones y los contextos en los que un cineasta consigue crear un artefacto para su disfrute en las salas de un espacio artístico son diversas. Sin embargo, tal y como me propongo evidenciar en este texto, los museos y centros de arte resultan, en algunos casos, el espacio ideal para la supervivencia de un determinado cine: el denominado "cine de autor». Una expresión que, como ya indicaba Vicente Benet en su interesante texto "Estilo, industria e institución: reflexiones sobre el canon del cine español actual» (febrero de 2005), implica no solo cuestiones formales y estéticas, de estilo, sino también, de comercialización y publicitación de una película. El estudioso identificaba dos modelos casi exclusivos (y no excluyentes) de apreciación del estilo presente en los textos cinematográficos en España, derivados a su vez de los discursos empleados para la comercialización de las películas: aquel que incide en que la película en cuestión responde a la creatividad de un "autor"; y el que la considera un producto industrial que contempla satisfacer las demandas del público.

En relación con el primero, Timothy Corrigan coincide en señalar que la recurrencia a la "autoría" ha tenido que ver con cuestiones relacionadas con la comercialización de las películas, se ha empleado como una estrategia comercial. Asimismo, indica que "today, even these modernist corrections, discussions or deconstructions of the romantic roots of auterism need to be taken another step toward recontextualizing them within industrial and commercial trajectories» (Corrigan en Triana-Toribio, 2008, p. 261); en la misma línea, María M. Delgado ha señalado recientemente que la "autoría» sigue siendo vigente como medio de análisis del cine español, debido a su demostrada utilidad para la visibilización y legitimación de determinadas películas y cineastas que, además, tienen un alcance global, especialmente por medio de su presencia en festivales, donde el cine español se convierte en un "«otro" seductor y deseable» (2015, p. 5).

Resulta imprescindible tener en cuenta el contexto transnacional en el que el (no ya el cine sino) el audiovisual español opera durante las últimas décadas. Éste contribuye de manera significativa a crear una imagen del estado nación en mercados foráneos. La presencia de productos elaborados por cineastas-autores-artistas españoles en centros de arte, museos y espacios galerísticos europeos ha contribuido a la consolidación de la etiqueta "autoría» para referirse a y promocionar la obra de dichos nombres propios, si bien en ocasiones lo ha hecho acudiendo a fórmulas específicas -que no suelen comprenderse dentro del propio estado nación.

Dando un paso más en la línea iniciada por Corrigan y Benet, Nuria Triana-Toribio emplea con éxito la expresión utilizada por vez primera por Benet (2005, p. 68), "directores mediáticos", para analizar la manera en que la categoría de "cineasta autor" es útil para "colocar el producto" en el mercado, gracias a un uso determinado de los distintos medios que permiten la promoción y exposición de la producción de figuras como Álex de la Iglesia, Isabel Coixet, y Pedro Almodóvar (2008).

Mi proposición es que ambas categorías resultan también provechosas en el caso de cineastas españoles que han migrado a los museos y centros de arte; un lugar que, pese a haber privilegiado durante las últimas décadas las salas temáticas construidas a base de asociaciones entre objetos culturales diversos frente a las salas monográficas dedicadas a la obra material de autores considerados como creadores aislados (Ávila, 2010, p. 249), las narrativas que despliegan sobre el arte gravitan aún, en muchos casos, en torno al "culto a la autoría". Es en este espacio donde determinados cineastas, cuya obra no encaja en los cauces industriales habituales, encuentran acomodo, así como consiguen apuntalar su condición autoral. 
En el caso español, la muestra Erice-Kiarostami. Correspondencias (2005-2008) y su continuación en Todas las cartas. Correspondencias fílmicas (2009-2011), impulsadas por el Centro de Cultura Contemporánea de Barcelona, que migraría a otros museos colaboradores (La Casa Encendida de Madrid, Centro Pompidou de París y Centro Cultural Universitario Tlatelolco de México), resulta un caso de traslación del cine al museo que fundó las bases de futuras iniciativas, así como, en lo que nos interesa aquí, la primera incursión en nuevas vías para la producción y promoción de un cine auspiciado bajo la categoría de «autoral». La iniciativa planteaba el intercambio fílmico entre un cineasta español y uno foráneo, según afirma el impulsor de ésta, Jordi Ballós, con la intención de crear afinidades, ya fuera desde la convergencia, ya (esto, previsiblemente, en el menor de los casos) desde la divergencia. Tras Víctor Erice y Abbas Kiarostami, se plantearon los binomios José Luis Guerín-Jonas Mekas, Isaki Lacuesta-Naomi Kawase, Fernando Eimbcke-So Yong Kim, Albert Serra-Lisandro Alonso y Wang Bing-Jaime Rosales. Concebidas como un espacio para crear comunidad, tal y como el impulsor de esta iniciativa expone en un texto, se trata de "an experience which (although this is not its main purpose) dissolves boundaries: boundaries between spectator and film; and geographcial boundaries as well, because what is particularly notable about exhibition cinema is its international orientation and circulation» (Balló y Pintor Iranzo, 2014).

Es por esto último que Enrique Fibla, en su estudio sobre el cine epistolar considera que, frente a estos ejercicios, el espectador

«se enfrenta no solo a la obra de tal o cual director por separado, sino a un conjunto que difumina la noción de autoría individual, una comunidad en su sentido más básico, simple y efectivo; el de la afinidad, la puesta en común, el intercambio, de una visión del mundo por otra, o la construcción de un puente entre ambas si se quiere».

Más concretamente,

"acostumbrados a la lectura del término autor desde una óptica individualista y acotada, las correspondencias ponen de relieve que la autoría también existe en común. Las imágenes que surgen de dichos encuentros están directamente influenciadas por las del interlocutor, por lo que el propio proceso creativo de corresponderse se convierte en parte de la obra» (mayo de 2014, p. 215).

Lo cierto es que esa interlocución presente en el ejercicio epistolar implica, más bien, una puesta en crisis de la "autoría» que, sin embargo, no deja de aludir y referenciar en cada caso, aunque sea de manera indirecta o incluso traumatizada, a la propia realidad expresiva de cada uno de los autores. Tal y como Fibla indica más adelante,

5 Jordi Balló resulta una figura clave para la inserción de propuestas de no ficción en el canon cinematográfico a través de la dirección de exposiciones en en el CCCB (1998-2011) pero también de la dirección del Máster en Documental de Creación de la Universidad Pompeu Fabra (1998-), en el que ha involucrado a cineastas como Pere Portabella, Joaquín Jordá, José Luis Guerín, Mercedes Álvarez e Isaki Lacuesta, entre otros; también, se encuentran comprometidos estudiosos del cine (Ángel Quintana), programadores, críticos (Carlos F. Heredero, director de Caimán.Cuadernos de cine) e incluso el director de coproducción de documentales de TV3 Jordi Ambrós. Su labor comprende tanto la producción, como la exhibición y la crítica (desde el diario La Vanguardia), formando una red consistente. 
«Para los participantes, contestar cada carta implica imaginar afinidades con las realidades geopolíticas que acaban de recibir, siempre desde el proceso activo de escribir en imágenes. Un ejercicio que expone los límites de la singularidad en el estar-en-común (Nancy, 1991: 41)» (mayo de 2014, p. 217).

No en vano, para Fibla

«el resultado de Todas las Cartas incide en el valor político de este intercambio entendido como negociación de realidades expresivas, en lugar de un proceso narcisista que se acomoda a la lógica neoliberal. Desde este punto de vista, se puede afirmar que gran parte de los intercambios que se producen en el entorno digital son más bien diálogos de sordos, los cuales buscan expresar un yo mucho más expansivo que inclusivo, poco interesado en establecer conexiones profundas con el otro. Algo que sí sucede en el proyecto epistolar del CCCB, donde el diálogo de singularidades muestra que la realidad siempre se puede poner en común» (mayo de 2014, p. 222).

De entre los participantes de dichas correspondencias, se encuentra un joven cineasta catalán que, tras esta primera incursión en el ámbito museístico, realizará proyectos que han ido a parar a salas de cine convencionales y a instituciones artísticas tanto nacionales como internacionales. Su trayectoria se caracteriza por la mutación, la migración y la reformulación, pues se configura a partir de procesos de relectura, recreación y revisión de obra propia que suele partir de textos escritos ajenos y que, con variantes o sin ellas, se aloja en lugares diversos. La presencia del cineasta en multitud de medios, donde se propone como abanderado del "cine de autor", así como su tendencia a la extravagancia y la provocación, le convierten en una manifestación particular de esos «directores mediáticos» que son conscientes de la oportunidad comercial que implica la asunción de la categoría de «autor» en un escenario comercial y de promoción que ya no solo se configura desde la black box, sino que también incluye el white cube. A continuación, exploraremos su trayectoria prestando atención a las mutaciones y migraciones de su obra, así como a las narrativas que la acompañan (mediante su exposición mediática y aquella surgida de parte de los propios sistemas involucrados, tanto cinematográficos como artísticos).

\section{Un cineasta-artista en el museo. Albert Serra: mutaciones y relec- turas bajo el signo del «autor»}

En la web catalanfilms\&tv, empresa financiada por el Departament de Cultura de la Generalitat de Catalunya, y que se define a sí misma como «motor de la internacionalización de las empresas audiovisuales catalanas» que «establece conexiones locales, nacionales e internacionales y promueve la presencia de productos y empresas catalanas en mercados y festivales» (http://catalanfilms.cat/es/sobre-nosotros), se anuncia un nuevo proyecto de Andergraun Films, la productora del cineasta catalán Albert Serra, realizado por él mismo. Éste consiste, según se indica en dicha web, en un largometraje de ficción planteado como un acercamiento al mundo del arte contemporáneo. Para aquellos que conozcan las entrevistas y declaraciones del cineasta, el título, I Am an Artist, les sonará autorreferencial.

Albert Serra ha sido definido por la crítica nacional e internacional como el enfant terrible del cine español, disidente, subversivo, provocador; unos adjetivos que 
también él ha promovido mediante sus declaraciones en prensa y entrevistas audiovisuales. Como indica Antoni Peris en su texto sobre el cineasta-personaje, mediante sus boutades, en las que «lanza como con cañón recortado, despreciando la mezquindad y la incultura en la industria del cine y los propios espectadores", Serra ha emprendido «una voluntariosa construcción de una figura contestataria, algo simplista, pero que [...] tiene mayor enjundia de la que podría parecer a primera vista» (Peris, 28 de septiembre de 2010).

Tal y como él mismo suele contar, sus inicios en el cine se encuentran alejados de la habitual formación en centros donde se aprende el lenguaje y la técnica audiovisuales. Por el contrario, estudió Filología Hispánica, Teoría de la Literatura y Literatura Comparada y un primer ciclo de Historia del Arte. En sus presencias públicas ensalza la literatura, la música y el arte (no así el cine) y confiesa un conocimiento de la técnica del medio cinematográfico limitado; aporta citas de cineastas y artistas y hace gala de un amplio conocimiento de ambos ámbitos.

Sus comienzos en el cine se producen en 2003, cuando realiza una primera película de manera amateur, Crespià, the Film, not the Village. Es con su segunda película, Honor de cavalleria (2006), que se proyecta en festivales como el de Cannes (festival que acogerá sus siguientes películas), el Festival de Rotterdam y el de San Sebastián, y obtiene premios en el Festival de Turín y en la Viennale, entre otros, con la que consigue una atención considerable por parte de la crítica. El largometraje parte del Quijote de Cervantes, un texto universalmente conocido que ha gozado de multitud de adaptaciones en el cine, algunas de las cuales se han convertido en "acontecimientos cinematográficos/culturales»: es el caso, por ejemplo, de la inacabada Don Quixote (Orson Welles, 1957-), que dio lugar a una reconstrucción polémica, llevada a cabo por el amigo y colaborador de Welles, Jesús Franco, que se proyectó bajo el título de Don Quijote de Orson Welles en la Exposición Universal de Sevilla de 1992; y del célebre (por complicado) proyecto en torno a esta figura de Terry Gilliam, cuyas desventuras fueron narradas en el documental Lost in La Mancha (Keith Filton y Louis Pepe, 2002), que el cineasta y cómico inglés finalmente logró terminar bajo el nombre de El hombre que mató a Don Quijote (2018).

La película de Serra se convierte en un «acontecimiento cinematográfico» dentro de una sección de la crítica especializada, en parte por implicar el descubrimiento de un joven cineasta que sorprende con un largometraje original que surge «desde los márgenes». Su responsable no duda en relacionar la figura en la que se basa la película con la suya propia:

«Soy español, fiel a una concepción española de la coherencia, ligada a la tradición del idealismo y del fanatismo. [...] Intentamos encontrar dinero público, pero el Estado español y la región catalana han decidido no ayudar a la película. Resulta finalmente coherente: Quijote es el carácter anti institucional por excelencia» (Serra en Palladino, Giugno 2018, p. 7).

Tal y como diversos estudiosos y críticos han coincidido en señalar, frente a versiones anteriores, lo característico del filme es la ausencia de acción y el uso de actores no profesionales. Contando con pocos medios, el formato digital permite a Serra realizar un largometraje, lo que, junto al uso de una trama deslavazada y la interpretación improvisada, da como resultado un filme en el que son los dos sujetos protagonistas, animados por Serra a una interpretación libre, quienes recrean la obra de Cervantes. El resultado implica, así, un cuestionamiento de los límites de la adaptación cinemato- 
gráfica (González de Canales Carcenery, 2017) y evidencia la tendencia a los procesos de reescritura que el cineasta catalán demostrará en sus siguientes proyectos. Esta primera película es valorada, desde distintos flancos, como una obra original, difícilmente explicable a partir de presupuestos contextuales/culturales; así, por ejemplo, el director de la sección independiente del festival de Cannes, Olivier Peré, la consideraría «una obra extremadamente radical, muy bella, en abierta ruptura respecto a numerosos filmes españoles y europeos actuales» (Díaz Cabiedes, 16/04/2013).

Desde este proyecto, la obra del cineasta catalán no ha sido más que una constante reescritura de referentes literarios variados: El cant dels ocells (2008) escenifica el trayecto de los Reyes Magos narrado en la Biblia; e Història de la meva mort (2012) recrea el encuentro imaginario entre Drácula y Giacomo Casanova. En estas obras destaca la gran independencia del producto resultante con respecto al de partida y la tendencia a evidenciar el artefacto como un "modo de lectura" propio (en palabras de Michel Serceau, 1999; a partir de Pérez Bowie, 2004: 279]). La apuesta por una reescritura que deja de lado la trama argumental del original y se centra en conseguir una cierta atmósfera, fruto de la "situación» surgida del "contagio» con dicho original, conlleva la necesidad de un espectador con un conocimiento previo y justifica las soluciones formales adoptadas en sus primeras películas, tal y como indica él mismo en una entrevista para un medio digital:

"como ya todo el mundo conoce la historia que cuento, ya no hay que centrarse en explicarla y uno puede estar más con los detalles, con lo irónico, con lo atmosférico, con varias cosas que normalmente en una película que no tuviera una historia conocida correrías el riesgo de caer en la confusión» (García Conde, 7 de enero de 2014).

Esta condición se encuentra también presente en aquellos de sus proyectos que consisten en la reformulación de trabajos propios anteriores. La invitación al cineasta, por parte de espacios artísticos, a emprender proyectos que encuentren un acomodo en un nuevo escenario ha servido a Serra para llevar a cabo reformulaciones diversas. Su primera colaboración con un espacio exhibitivo consiste en la serie de 14 capítulos Els noms de Crist (2010), incluida en la exposición del MACBA Esteu a punt per a la televisió? ${ }^{6}$, comisariada por Chus Martínez. Considerado como un trabajo complementario a la muestra (como también los encargados a reconocidos artistas españoles como Johan Gimonprez e Isidoro Valcárcel) y rodada en los espacios del museo, la serie aborda, como se explica en el folleto explicativo de la exposición, la cuestión de la traducción, en «el intento de casar un mundo con otro, como la literatura con el cine, el cine con el museo, la televisión con el género expositivo».

Este producto logra traspasar el terreno artístico para proyectarse en la sección oficial de los festivales de Locarno (2011) y Rotterdam (2012); tal y como se indica en la web del festival, a manera de réplica del folleto de la exposición, esta pieza, desplazada de la institución museística a la cinematográfica, «aborda los desafíos del proceso de traducción, de la literatura al cine y del cine al museo y del museo a la televisión». Se trata, así, de un ejercicio que, desde su propio texto, se plantea como una reflexión

6. Inspirada en la obra de Fray Luis de León, esta propuesta abre su metraje con «una pel-lícula d'Albert Serra" (la cursiva es nuestra), pero se encuentra disponible en la web del centro bajo la categoría de "Altres/Videos d'artista" (la cursiva es nuestra). https://www.macba.cat/video-albertserra-noms-de-crist-01. 
sobre la adaptación y la intermedialidad y que, como comprobamos, admite su migración de un espacio exhibitivo a otro, así como, también, de un escenario nacional a otro internacional.

Su siguiente incursión en terreno artístico es El senyor ha fet en mi meravelles (2011), surgida de la iniciativa Cinergias, del CCCB, que, tras ampliar la nómina de diálogos entre cineastas catalanes y extranjeros, se incluiría finalmente en la exposición Todas las cartas. Correspondencias fílmicas del CCCB. Construida a partir de la idea de un diálogo con otro cineasta (como el resto de cartas fílmicas incluidas en la muestra), la propuesta de Serra se plantea, sin embargo, de manera autónoma respecto a su supuesto interlocutor, Lisandro Alonso, así como también ajena a la norma relativa a la duración (debía tratarse de un cortometraje) para concebirse como una mirada acerca de las dificultades de la libertad creativa mediante la referencia a la propia obra fílmica anterior: se trata de una recreación del making-off de Honor de cavalleria donde se opta por mostrar los tiempos muertos del equipo frente a los (supuestos) momentos de rodaje. La pieza resultante, junto con la del propio Alonso, se proyectó después en el festival de Locarno en sección fuera de concurso.

Dos años después de esta iniciativa, que fuera acogida por el Centro Pompidou, dicho centro, animado por los galardones obtenidos con la nueva película História de la meva mort (2013), considerada por The New Yorker como una de las mejores películas del año, emprende la realización de una retrospectiva de su trabajo. Dada la cinefilia declarada del cineasta, se decide la presencia de una "Carta blanche» que revele sus influencias fílmicas: es la oportunidad de poner en relación la obra propia con obra ajena, estableciendo una constelación de cuerpos aislados de los que se promueve una lectura composicional.

El centro de arte francés le considera "no solo un gran cineasta» sino también "un artista del siglo XXI", apuntalando su presencia en el centro artístico y aludiendo a sus experiencias previas en el seno del museo; además, en la introducción del folleto de la exposición, escrita por el por entonces presidente del Pompidou, Alain Seban, se propone un vínculo con otro artista español que goza de la admiración del propio Serra pero también del reconocimiento universal: "Recordemos [...] la exuberancia proteica de Dalí, otro extravagante catalán que ha marcado su tiempo y de quien el cineasta admira la mezcla de belleza y el gusto por la burla» (Seban, 2013). Se le vincula, así, a un artista universal, nacido también en Cataluña, al que el cineasta suele aludir en sus intervenciones públicas. En la entrevista incluida a Serra en el folleto de la exposición, éste lleva a cabo una legitimización del «cine de autor» como práctica artística y alude a su sintonía con el extravagante pintor catalán:

"Debido a mis orígenes catalanes, puedo entender mejor su psicología; en particular, sus deseos, sus obsesiones, e interpretarlos mejor que la mayoría de los investigadores. [...] trato de hacer que su ejemplo me sea útil. Es una admiración interesada» (Pras, 2013).

La retrospectiva sirve para legitimar al cineasta y enraizarlo a una determinada tradición artística por medio de la recurrencia a un nombre propio que puede ayudar al espectador francés a "situar" a este nuevo y joven "artista-cineasta». Para apuntalar esta relación, entre las actividades complementarias organizadas, se encuentra una "discusión entre las 21h y el amanecer, entre el cineasta Albert Serra y Hans Ulrich 
Obrist, codirector de exposiciones de la Serpentine Gallery (Londres), en torno a Salvador Dalî

Asimismo, en dicha exposición retrospectiva, al cineasta se le integra en determinada tradición cultural española por medio de un motivo que aún sigue presente en el imaginario visual español, especialmente desde el extranjero: los toros. De entre las actividades complementarias a la proyección de su trabajo, se incluye una el sábado 27 de abril, a las 17.30, en una «ipequeña sala de toros!» [las exclamaciones son del original], que se anuncia de la siguiente manera: "Albert Serra se encuentra acompañado de críticos y amigos para abordar las corridas de toros, símbolo de la cultura española, de la que es aficionado desde siempre, a través de su estética y su ética». Al cineasta le acompañan defensores de "la fiesta" como: el reconocido pintor mallorquín Miquel Barceló; el torero Luis Francisco Esplá; y el filósofo francés Francis Wolff, que, entre otros textos, había publicado Filosofía de las corridas de toros (2008) y 50 razones para defender la corrida de toros (2010). En un país que conoce de manera directa el "espectáculo taurino» (tiene un desarrollo significativo en el sur del país), pero que también lo reconoce por mediación de figuras como Picasso, artista que ha provocado debates institucionales acerca de la "nacionalidad" de su obra, la figura de Serra resulta fácilmente «acoplable» mediante la recurrencia a motivos que articulen una narrativa asumible por reconocible.

En la retrospectiva del trabajo del cineasta catalán, se incluye, por primera vez en Francia, la proyección de uno de sus últimos proyectos: una suerte de performance fílmica para la Documenta de Kassel de 2012, concebida a partir de tres textos: Conversaciones con Goethe, de Johan Peter Eckermann (1836-1848), Las conversaciones de sobremesa de Hitler. 1941-1944 (Hugh Trevor-Roper, 1953) y Fassbinder por Fassbinder (1969-1982) (Robert Fisher [ed.], 2004). El título de la pieza, Los tres cerditos, alude de manera irónica a los tres momentos históricos clave en la construcción de la identidad cultural europea bajo la comparecencia de tres figuras imprescindibles de la historia alemana. La predilección del cineasta catalán por las interpretaciones libres se nutre aquí de una presencia de la palabra no siempre presente en sus producciones fílmicas anteriores. También, el espacio resulta significativo en cuanto aporta un escenario histórico (uno de los cuatro lugares seleccionados por el cineasta es una antigua fábrica textil en desuso que fue cuartel general de los nazis). Se trata de una filmación realizada durante los 100 días que dura la exposición, proyectadas tras su montaje cada noche y, en su resultado final, 24 horas al día durante ocho días (8-16 de septiembre). Es en este proyecto en el que se hace evidente lo que diversos cineastas (incluido el propio Serra), migrados a los centros artísticos, han señalado convenientemente: en el espacio del arte, no hay constricciones en cuanto a la duración de la propuesta. La temporalidad en este proyecto del cineasta catalán resulta de manera directa de su interacción con los espacios artísticos.

7. En cuanto a la identificación entre Albert Serra y la cultura catalana, en 2015, el cineasta será elegido para representar a Cataluña en la Bienal de Artes Visuales de Venecia con un proyecto seleccionado por la reconocida comisaria Chus Martínez titulado La singularitat. La figura de Albert Serra resulta también interesante para la consecución de un estudio que, de manera específica, analice cuestiones relacionadas con lo (trans)nacional, de las que, por cierto, el cineasta no es ajeno: "Todo el cine interesante ahora es transnacional, a todos los niveles, pero sobre todo a nivel de percepción y de juicio crítico» (González De Canales Carcenery, J., julio-diciembre de 2018, p. 119). 
Así, su proyección posterior en el Centro Pompidou, en una sala al estilo de las de cine (black box insertada en el white cube), una vez abandonado el espacio que albergó el proyecto original, que definía la temporalidad de la propuesta, implica la asunción de una nueva duración: se proyectará en varias sesiones de 10 horas cada una. En este traslado, la pieza se convierte, más bien, en "documento» de la situación de la que surgió, perdiendo una parte significativa de su efecto original. Esta mutación hace que el resultado se encuentre más cercano a una «exposición de cine» más que al "cine de exposición» (Samaniego, 2010); aunque revele su origen fragmentario y espontáneo, su disposición en la sala anula ambas cualidades a favor de la continuidad y de la solidificación de su original temporalidad desenfadada.

Las migraciones y mutaciones serán, a partir de entonces, una tónica en su trayectoria. Su siguiente largometraje, La mort de Luis XIV (2016), daría lugar a múltiples productos exhibidos en espacios de índole variada. Inspirada en las memorias de Louis de Rouvroy, Duque de Saint-Simon, la película escenifica los últimos momentos del monarca y cuenta, esta vez, con un actor profesional que fue habitual en el cine francés de la Nouvelle Vague: el ya veterano Jean Pierre Leaud. Interpretada por parte de la crítica como una metáfora de la muerte del cine, lectura que Serra ha cuestionado de manera implacable, su posterior multiplicación en diversos formatos hará que se trate, más bien, de la evidencia de las posibilidades de supervivencia del cine mediante su multiplicación y diversificación en productos diversos listos para alojarse en espacios distintos.

La película tiene, en realidad, su origen en un proyecto previo no llevado a cabo: la recreación, mediante performance, de la muerte del rey francés en el hall del Centro Pompidou empleando al actor mítico, introducido en una urna de cristal durante varias semanas. Un año después de estrenado con éxito de crítica el largometraje, el 13 de enero de 2017, la galería Graça Brandão de Lisboa recupera el proyecto original y presenta la performance bajo el título de Roi Soleil. Las diferencias entre película y performance son: la recreación en directo, sin mediaciones, de una situación que se desarrolla ante los ojos de los visitantes, que entran y salen de la sala a su antojo; la importancia del espacio ("teatralizado" mediante un neón rojo que inunda la sala) y del tiempo (en una experiencia en la que es el visitante quien dispone el principio y el fin); la trayectoria inversa que propone la performance respecto a la película en lo relativo al personaje como figura mítica, tal y como explica el propio Serra: "La película anterior partía de arriba e intentaba ir muy abajo. Ahora la idea es la contraria: se parte de abajo para, desde su miseria, intentar tocar siquiera parte de su grandeza" (Martínez, 2018); y la recurrencia, esta vez, al intérprete de sus primeras películas en el cine de Serra, el actor no profesional Lluís Serrat.

Curiosamente, de esta performance surge una película, resultado de la filmación de la primera, con el mismo título (parece que el deseo de disimular las deudas es mínimo). La experiencia que propone esta nueva mirada al largo, anodino a veces y terrible siempre proceso de muerte de uno de los monarcas más poderosos de Francia pretende mostrar detalles que, durante la performance, escapan al ojo. Los planos intensifican la fragilidad de un cuerpo, el del actor que por momentos se transforma en rey que muere y que lo hace sin instrucciones acerca de cuándo sucederá tal hecho y sin referencias temporales de ningún tipo. Captado el deceso con una sola cámara (parece que no estaba prevista una incursión fílmica sobre la acción), la filmación de 29 horas se condensa en 61 minutos, en lo que resulta un ejercicio (no tan habitual) de traslación de una instalación a una película que transitará por festivales de cine como, 
por ejemplo, FID Marseille, cuya sinopsis, escrita por Jean-Pierre Rehm, termina de nuevo aludiendo a dos grandes artistas españoles universales: Dalí y Buñuel.

La última incursión en la imagen en movimiento por parte de Serra es la videoinstalación Personalien (2019), de la que derivará la película Liberté (2019). A su vez, la videoinstalación tiene su origen en una obra de teatro que Serra desarrolló en la Berlinale un año antes. Así lo cuenta para un medio escrito:

"Cuando presenté la obra teatral durante la Berlinale del 2018, en un bosque, mucha gente me comentó que aquel material era idóneo para explorar las dinámicas entre voyerismo y exhibicionismo, y que ganaría mucho si se hacía en formato cinematográfico. Rodé la película y, mientras la estaba montando, me ofrecieron el proyecto del Reina Sofía. No me daba tiempo a rodar nada nuevo, así que decidí usar parte de lo que había rodado para Liberté. A grandes males, grandes remedios» (Salvà, 19/05/2019).

La obra de teatro de dos horas y media de duración, inspirada en los textos del Marqués de Sade, es un "tableaux vivant de la vieja Europa" donde varios expatriados, que huyen del gobierno conservador de Luis XVI (1774), se encuentran con el pensador Duc de Walchen mientras se dirigen a Alemania para imponer el libertinaje. En la revista newyorkina Artforum señalan sobre la representación teatral: "The most immediately striking thing about this Serra play is the degree to which it resembles, in theme and effect, a Serra film", añadiendo que la obra "attests to the sheer force of his idiosyncratic aesthetic signature» (Lim, 16 March 2018). Si bien la recepción de la obra por parte del público estuvo, al parecer, influenciada por los reproches surgidos por el nombramiento del nuevo (y polémico) director del teatro Volksbühne, Chris Dercon, la crítica cinematográfica considera ésta desde el universo fílmico de Serra (Lim y Sullivan, March 13 2018). La recurrencia del cineasta a la actriz fetiche y esposa de Fassbinder, Ingrid Caven, para la interpretación protagonista, y de Helmut Berger, ligado al cine de Visconti, incita a su vez una lectura de la obra desde el cine.

Respecto a la videoinstalación del MNCARS, disponible entre el 27 de febrero y el 13 de mayo de 2019, forma parte del programa "Fisuras", que pretende, al contrario que el resto de las exposiciones, el fomento de obra nueva por parte de artistas a exponerse en un espacio determinado del museo de manera temporal. Serra dispone, en la tercera planta del edificio Sabatini dos proyecciones enfrentadas de varios metros cada una. En palabras del propio Serra, ésta consiste en "Un bosque, un área de 'cruising' en el siglo XVIII, dos pantallas y el espectador en medio de esos encuentros azarosos" (Martínez, 25/02/2018). El estatismo de la obra de teatro (tanto de la escena como de los asistentes) se pierde aquí. A partir de un arco narrativo conjunto, que va desde la noche al amanecer, se suceden escenas de tipo sexual, en algunos momentos bastante explícitas, para conformar un lugar en el que el visitante se interna bajo las sombras de la sala oscura con la (im)posibilidad de elegir qué proyección ver en cada momento; como indica el propio Serra: «el proyectar en dos pantallas da lugar a una multiplicidad de puntos de vistas, que es parte del placer y la curiosidad" (Martín, 25 de febrero de 2019). El montaje de las escenas que se suceden en cada una de las pantallas ha sido realizado teniendo en cuenta su disposición conjunta en el espacio del museo; según indica:

"pongo al espectador en medio de la acción, que disfruta con un sonido y una imagen que a veces se sincronizan, a veces que no... Un hombre mira por un catalejo y se ve a sí mismo, de repente otro corre a esconderse y no sabemos por qué. He meditado mucho 
el resultado y he usado solo la parte más atmosférica y conceptual de lo que grabamos durante 20 días» (Belinchón, 28 de febrero de 2019).

La tensión entre intimidad y exhibicionismo conduce, como señala el propio director del museo, a un cuestionamiento de la propia mirada por parte del visitante (Martín, 25 de febrero de 2019); así como, también, a un contraste entre la representación del deseo sexual inspirada por Sade y la idea actual del deseo como «una pulsión controlada, capitalista, un intercambio de bienes» (De Pedro, 27/02/2019), que sucede, además, en el interior de un museo. Se trata de un proyecto que obtendría la atención de los medios y que evidencia lo que el cineasta catalán suele señalar respecto a las posibilidades del cineasta en el museo: «El que encarga en arte lo que quiere al final es verse sorprendido o desafiado por el artista. En el cine, productor y espectador lo que desean es verse confirmados en sus expectativas» (Serra en Díaz-Guardiola, 02/04/2019).

De nuevo, junto a la videoinstalación, se programa en el museo un ciclo de películas comisariado por el propio Serra bajo el título «Yo también. Deseo y delito. Carta blanca a Albert Serra" (alusión al movimiento Me Too que habla también del carácter contemporáneo de la videoinstalación -pese a transcurrir la acción en el siglo XVIII-). En dicho ciclo se muestran diversas manifestaciones del deseo en el cine y se aporta un universo fílmico que muestra la personalidad del autor por medio de sus gustos cinematográficos. Su punto de anclaje es, como él mismo indica, "las formas rompedoras, que dialogan con algunas transgresiones de los sesenta, y la obsesión por la creación de imágenes inéditas de verdad, con atmósferas que no se han visto nunca con anterioridad. En Personalien es muy difícil identificar de dónde surgen las imágenes que ves, ni saber el porqué de su existencia. Son difíciles y retienen su misterio hasta el final. Lo mismo sucede con las películas que he escogido" (Dossier Albert Serra. Personalien, 2019). Se incluyen películas muy diversas cuyo punto de unión es la transgresión y la polémica: hay filmes canónicos del experimental (Meat Joy, de Carole Schneemann [1964] y Flesh, de Paul Morrissey [1968]) en diálogo con otros menos conocidos (Emperor Tomate Ketchup, de Shuji Terayama [1971]), así como documentales (Models, de Ulrich Seidl [2008] y Las confesiones de Winifred Wagner, de Hans-Jürgen Syberberg [1978]), un melodrama trans (Morir como un hombre, de João Pedro Rodrigues [2009]) y hasta una película pinku eiga (exploitation japonesa; Cuando el embrión es un cazador furtivo, de Koji Wakamatsu [1966]).

Por último, la película Liberté (2019), de 120 minutos, indaga en los fueras de campo y la cualidad voyeurística propia del cine. La narrativa, pese a su carácter fragmentario y a que transcurre en un solo espacio y durante una noche, se instala en una estructura con una temporalidad más clara que en la videoinstalación; no en vano, el espectador del filme, frente al visitante del museo, lo verá de principio a fin. En su versión cinematográfica, de 133 minutos de duración, el motivo del deseo se convierte en una alusión a la pulsión escópica característica del medio mediante el uso de una estructura narrativa fragmentaria y elíptica, tal y como señalarán los críticos de cine (por ejemplo, Yáñez, 19/05/2019). 


\section{Conclusiones}

"We have to avoid the word cinema. Change the word, never use cinema: people, rich people, when they hear cinema, they think about Alfred Hitchcock, about Rodolfo Valentino, Humphrey Bogart; they would never put money on that. We have to work just for the art world. I think it's the future. Cinema is over... Stop cinema; the TVs will not finance anymore on that, that's sure, so what do you want us to do?... Give them cinema and give us artw.

Esas son las palabras de Albert Serra incluidas en el folleto de la Tate Gallery sobre la retrospectiva sobre su cine, llevada a cabo entre el 11 y el 20 de marzo de 2015.

El cineasta resulta una figura idónea para estudiar los diferentes procesos de migración de unos espacios a otros en la búsqueda de lugares que permitan el desarrollo de una trayectoria consistente en el complejo escenario actual. El propio Serra es consciente de que el interés en desarrollar desde diversos medios una misma temática es una lógica que, más allá de cuestiones estéticas, responde principalmente a motivaciones económicas. Como el cineasta explica, "antes hacías algo que tenía éxito y casi tenías garantizado el siguiente proyecto. Pero, sin medios, volvemos como a los orígenes y nos sentimos "pioneros»" (Díaz-Guardiola, 02/04/2019).

Su posición como creador revela ya una pulsión intermedial:

"Casi cogí de cada arte una cosa: de la música tomé la actitud, de hacerlo a tu manera (el rock and roll), de la literatura, la cosa más formalista, importa la construcción formal de la película; de las artes plásticas, lo lúdico, lo subversivo, también la fascinación visual pura, la audacia; y de lo que menos, el cine, por su tendencia humanista» (Pérez Guevara, J. A. / 242 películas después).

Sin embargo, como evidencia también esta declaración, la diversidad de productos revelan un único punto en común: que responden a una misma «autoría». Tal y como indica Triana-Toribio a partir de David Bordwell, "Director`s statements of intent guide comprehension of the film, while a body of work linked to an authorial signatura encourages viewers to read each film as a chapter of an entire oeuvre» (Bordwell citado en Triana-Toribio, 2008, p. 264).

$\mathrm{Si}$, por una parte, en los contextos en los que se produce y exhibe, la obra de Serra no se explica en términos contextuales (más que para aludir a la exclusividad de sus propuestas), sí se narra en conexión con otras obras, nombres propios y fenómenos cinematográficos que permiten: por una parte, vincularlo a determinadas tradiciones fílmicas, gracias en parte a la presencia en su trabajo más reciente de actores-mito vinculados a determinados "cineastas-autores" reconocidos y a movimientos fílmicos clave en la historia del cine; por otra, y de manera predominante en escenarios foráneos, situarlo dentro de una tradición cultural concreta, la española, mediante la recurrencia a un imaginario con décadas de pervivencia y expresiones significativas en el ámbito artístico y cinematográfico (de autor); y, por último, consolidar la personalidad del "autor-cineasta» mediante la exposición de sus gustos fílmicos que, por más variados que sean, mantienen además una tónica en común: la provocación y la radicalidad.

Sus trabajos son, además, ejercicios que trabajan en el nivel de lo meta fílmico, e incluso surgen unos derivados de otros, lo que permite la configuración mental de la obra del cineasta como compacta y coherente. Se cumple, también, la condición del 
"autor» en su obra: la consideración de ésta a partir de la identificación de un estilo que, aun con ciertas digresiones, es reconocible (y vendible). A este respecto, la constancia manifestada por el equipo que le acompaña en la mayor parte de sus proyectos (ya sean estos fílmicos, artísticos o teatrales) ${ }^{8}$, así como la consecución de un método de trabajo consistente, consigue dotar de continuidad a las diversas iniciativas que éste emprende.

Albert Serra es un "director mediático", consciente de que los cineastas deben ser mediáticos o, si no lo son, serán ignorados (Benet en Triana-Toribio, 2008, p. 260). Su presencia en medios diversos (televisión, prensa, Internet) permite incluirlo dentro de la nómina de cineastas que asumen la necesidad de construir un relato coherente y claro acerca de su obra, que se explica principalmente por medio de la recurrencia a su condición autoral; algo a lo que colaboran también los festivales de cine y las instituciones museísticas. Tal y como Triana-Toribio indica, «los directores españoles se están convirtiendo en mediáticos [...] como respuesta a las nuevas condiciones en las que operan, y necesitamos contextualizar su estatus dentro de sus estrategias comerciales» (262). Serra revela la importancia de ir más allá del análisis relativo al producto de las migraciones hacia otros medios para encontrar las circunstancias y condiciones en que dichas migraciones se producen. Pues no solo migran y mutan las obras; también lo hacen los discursos sobre éstas, que, en casos como el que abordamos, consiguen construir una narrativa consistente a partir de la capacidad aglutinadora y legitimadora de la categoría de "autor».

\section{Bibliografía}

Alonso García, L. (coord.) (2003). Once miradas sobre la crisis y el cine español. Madrid: Ocho y Medio.

Ávila, A. (2010). Los viejos y los nuevos museos. En J. A. Ramírez(ed.), El sistema del arte en España (pp. 157-278). Madrid: Cátedra.

Balló, J. y Pintor Iranzo, I. (2014). Exhibition Cinema: A Crossroads between the Cinema and the Museum in Contemporary Spanish Filmmaking. Hispanic Research Journal, 15 (1), 35:48. Recuperado de: doi.org/10.1179/1468273713Z.00000000072.

Belategui, O. (30 de abril de 2019). Víctor Erice regresa fascinado por Bilbao. El Correo. Recuperado de: https://www.elcorreo.com/butaca/cine/victor-erice-regresa-20190429162230-ntrc. html.

Belinchón, G. (28 de febrero de 2019). Albert Serra lleva el sexo del siglo XVIII al Reina Sofía. El País. Recuperado de: https://elpais.com/cultura/2019/02/27/actualidad/1551290935_924331. html.

Benet, V. J. (febrero de 2005). Estilo, industria e institución: reflexiones sobre el canon del cine español actual. Archivos de la Filmoteca 49, 66-81. Recuperado de: http://www.archivosdelafilmoteca.com/index.php/archivos/article/view/308

Català, J. M. (abril de 2012). El cine desplazado. Archivos de la Filmoteca. 69, 79-91. Recuperado de: http://www.archivosdelafilmoteca.com/index.php/archivos/article/view/32/31.

De Felipe Martínez, P. (ed.). (enero -junio de 2012). Cine en el museo. L'Atalante Revista de estudios cinematográficos, 13.

8. Agradezco a Alberto Cabrera Bernal la atención sobre este punto. 
De Pedro, G. (27/02/2019). "Personalien" de Albert Serra. Deseo liberado / Mirada coartada. Otros cines Europa. Recuperado de: http://www.otroscineseuropa.com/personalien-de-albert-serra-deseo-liberado-mirada-coartada/.

De Tuesta, M. J. (3 de noviembre de 2006). «La industria no permite riesgos». El País. Recuperado de: https://elpais.com/diario/2006/11/03/cine/1162508401_850215.html.

Delgado, M. M. y Fiddian, R. (2015). Spanish Cinema 1973-2010: Auterism, Politics, Landscape and Memory. Manchester: Manchester University Press.

Deltell, L. y García Fernández, E. C., (noviembre de 2013). La promoción fílmica en el universo digital. Hacia el ocaso de la exhibición cinematográfica en España. Historia y comunicación social 18, 203-217. doi: dx.doi.org/10.5209/rev_HICS. 2013.v18.44237.

Díaz Cabiedes, R. (16 /04/2013). Hitler, Goethe y Fassbinder, tres cerditos en 101 horas de cine. El Confidencial. Recuperado de: https://www.elconfidencial.com/cultura/2013-04-16/hitlergoethe-y-fassbinder-tres-cerditos-en-101-horas-de-cine_495539/

Díaz-Guardiola, J. (02/04/2019). Albert Serra: «Lo que interesa es lo que imaginas, no lo que ves. Todos vemos el mismo mundo». ABC. Recuperado de: https://www.abc.es/cultura/cultural/ abci-albert-serra-interesa-imaginas-no-todos-vemos-mismo-mundo-201904020200_noticia. html.

Dossier Albert Serra. Personalien (2019) MNCARS.

Dossier Divine Visionaries and Holy Fools. Tate Modern. Recuperado de: http://andergraun. com/files/ART/Tate_Bro00.pdf

Fibla, E. (mayo de 2014). Cine epistolar: imaginación y política del intercambio estético. Kamchatka. Revista de análisis cultural, 3, 207-226.

García Conde, P. (7 de enero de 2014). Entrevista a Albert Serra. Transit. Cine y otros desvíos. Recuperado de: http://cinentransit.com/entrevista-a-albert-serra/.

González De Canales Carcenery, J. (julio-diciembre de 2018). Albert Serra. Para un cine de artificio y naturalismo. L'Atalante. Revista de estudios cinematográficos, 26. Recuperado de: http://www.revistaatalante.com/index.php?journal=atalante\&page=article\&op=viewFile\&path[]=661\&path[]=491.

González de Canales Carcenery, J. (2017). El cine de Albert Serra: apropiación y reinterpretación fílmica de los clásicos literarios. Fotocinema. Revista científica de cine y fotografía, 14, 83-98. Recuperado de: http://revistafotocinema.com/index.php?journal=fotocinema\&page $=$ article $\&$ op $=$ view $\&$ path $\% 5 \mathrm{~B} \% 5 \mathrm{D}=398 \&$ path $\% 5 \mathrm{~B} \% 5 \mathrm{D}=389$.

Heredero, C. F. (mayo de 2007). Miradas hacia el futuro. Cahiers du cinéma España 1, 10-32.

Jarque, V. (abril de 2012). Dentro del museo y/ o fuera del lugar. Archivos de la Filmoteca 69, 92-103. Recuperado de: http://www.archivosdelafilmoteca.com/index.php/archivos/article/ view/27/26.

Lim, D. (16 March 2018). Liberté or Death. Artforum. Recuperado de: https://www.artforum. com/performance/dennis-lim-on-albert-serra-s-liberte-74639.

Martín, P. (25 de febrero de 2019). Albert Serra explora la «intimidad sexual» en el Museo Reina Sofía. EFE. Recuperado de: https://www.efe.com/efe/espana/cultura/albert-serra-explora-la-intimidad-sexual-en-el-museo-reina-sofia/10005-3908445.

Martín Patino, B. (2008). De espejos y nieblas en los campos charros. Basilio Martín Patino. Espejos en la niebla. Madrid: Círculo de Bellas Artes.

Martínez, B. (25/02/2019). Una videoinstalación de Albert Serra convierte al espectador en voyeur de una zona de 'cruising' del siglo XVIII. El Periódico. Recuperado de: https:// www.elperiodico.com/es/ocio-y-cultura/20190225/videoinstalacion-personalien-albert-serra-convierte-espectador-voyeur-zona-cruising-siglo-xviii-reina-sofia-7324099.

Palladino, N. (Giugno 2018). Honor de Cavalleria, riflessioni sul `quijotédi Albert Serra. Rassegna Iberistica, 41 (109).

Pérez Bowie, J. A. (2004). La adaptación cinematográfica a la luz de algunas aportaciones teóricas recientes. Signa, 13, 277-300.

Pérez Guevara, J. A. / 242 películas después. Entrevista a Albert Serra. Recuperado de: https:// www.youtube.com/watch?v=ww0xnY63wqI. 
Peris, A. (28 de septiembre de 2010). Albert Serra: entre el prestigio y el malditismo. Transit. Cine y otros desvíos. Recuperado de: http://cinentransit.com/albet-serra-entre-el-prestigioy-el-malditismo/.

Pras, S. (2013). Conversation avec Albert Serra. En Serra. Albert Serra/Lisandro Alonso. Cinéastes en correspondance. Centre Pompidou.

Quintana, Á. (2012). Después del cine. Imagen y realidad en la era digital. Barcelona: Acantilado.

Rosenbaum, J. y Martin, A. (2003). Movie Mutations: The Changing Face of World Cinephilia. Londres: BFI.

Salvá, N. (19 / 05 / 2019). Albert Serra. "No me gusta gustar. Me siento más a gusto en la provocación». El Periódico. Recuperado de: https://www.elperiodico.com/es/ocio-y-cultura/20190519/entrevista-albert-serra-estreno-liberte-festival-cannes-7463246

Samaniego, A. (2010). ¿Cine de exposición o exposición de cine? Secuencias. Revista de historia del cine, 32 (segundo semestre). Recuperado de: https://revistas.uam.es/secuencias/article/ view/3991/4251

Seban, A. (2013). Albert Serra. Artiste du 21éme siècle. En Serra. Albert Serra/Lisandro Alonso. Cinéastes en correspondance. Centre Pompidou.

Sullivan, D. (March 13, 2018). Festivals: Berlin 2018. Film Comment. Recuperado de: https:// www.filmcomment.com/blog/festivals-berlin-2018/.

Tranche, R. R. (abril de 2012). De la pantalla al lienzo: cine proyectado y cine expuesto. Archivos de la Filmoteca 69, 74-79.

Triana-Toribio, N. (autumn 2008). Auterism and Commerce in Contemporary Spanish Cinema: directores mediáticos. Screen, 49 (3), 259-276.

Uroski, A. V. (2010). El juguete filosófico como modelo: Duchamp, Breer y la emergencia del cine en el espacio expositivo durante la posguerra. Secuencias. Revista de historia del cine 32 (segundo semestre), 34-58. Recuperado de: https://revistas.uam.es/secuencias/article/ view/3986/4246.

Uroski, A. V. (2014). Between the Black Box and the White Cube. Chicago: The University of Chicago Press.

Weinrichter, A. (ed.) (2010). El cine en el espacio del arte. Secuencias. Revista de Historia del cine, 32 (segundo semestre).

Weinrichter, A. (mayo de 2006). De película. El cine se instala en el museo. Exit Express, 20, 8-13.

Yáñez, M. (19/05/2019). Albert Serra despoja el deseo carnal y fílmico en Cannes con 'Liberté'. Fotogramas. Recuperado de: https://www.fotogramas.es/festival-de-cannes/a27518526/ albert-serra-liberte-pelicula-cannes/.

Zunzunegui, S. (2010). Alianza y condena. El cine y el museo. Secuencias. Revista de historia del cine 32 (segundo semestre), 75-88. Recuperado de: https://revistas.uam.es/secuencias/ article/view/3988/4248. 